\title{
Trichloroethylene Induced Cancer in Animals and Its Relevance to Humans
}

\author{
Trevor GREEN \\ Zeneca Central Toxicology Laboratory
}

\begin{abstract}
Trichloroethylene Induced Cancer in animals and its relevance to Humans: Trevor Green. Zeneca Central Toxicology Laboratory-Trichloroethylene has been manufactured on an industrial scale since the beginning of this century. During that time widespread human exposure has occurred in industry and in the general population through the environment and from its uses in medicine, food and consumer products. Following the discovery in 1976 that trichloroethylene was an animal carcinogen, there have been numerous animal toxicology and human epidemiology studies evaluating the risks associated with exposure to this chemical. Trichloroethylene has been shown to cause tumours in both rats and mice in lifetime bioassays, principally liver and lung tumours in the mouse and kidney tumours in the rat. The mechanisms involved in the development of these tumours have been studied in detail and have been shown to be either species specific or a result of the use of cytotoxic dose levels. There is little or no evidence for genotoxicity playing a major role in these mechanisms. In mice, liver tumours are associated with peroxisome proliferation and increased cell division, the lung tumours are linked to cell damage and increased cell division. None of these effects are seen in rats due to metabolic and pharmacokinetic differences nor can they be replicated in human tissues. The low incidences of rat kidney tumours seen in some cancer bioassays appear to be linked to high dose toxicity. Human epidemiology studies based on large well defined cohorts support the findings of the mechanistic studies in animals and the overall conclusions that trichloroethylene is not a cancer hazard at current occupational and environmental levels.

(J Occup Health 1997; 39: 261-273)
\end{abstract}

Key words: Trichloroethylene, Carcinogenicity, Epidemiology. Human hazard assessment

Trichloroethyene is a colourless, volatile liquid

Received March 26, 1997; Accepted April 18, 1997

Correspondence to: T. Green, Zeneca Central Toxicology Laboratory, Alderley Park, Macclesfield, Cheshire, U.K. SK121HY which has been manufactured and used extensively since the beginning of this century. Today, it is used primarily in metal degreasing and as a solvent in the textile and chemical industries, but historically it has been used as an inhalational anaesthetic and as an additive in drugs, food and consumer products. Consequently, widespread human exposure has occurred ${ }^{1,2)}$ principally by inhalation of trichloroethylene vapour, and to a lesser extent via the skin and by ingestion. During the last 20 years, the potential for adverse effects on human health from trichloroethylene exposure, particularly the risk for cancer, has been studied in both laboratory animals and in humans exposed either occupationally or through the environment e.g. via drinking water.

The question of whether trichloroethylene presents a carcinogenic hazard to man has given rise to much debate. Unfortunately, the animal toxicology of trichloroethylene which is normally used as the basis of human health assessments is at times both confusing and conflicting. As with many of the older industrial chemicals there has been a multiplicity of studies which have, on occasion, increased the uncertainty rather than clarified the potential human health risks. For example, it is accepted that trichloroethylene is carcinogenic in animals, causing principally liver and lung tumours in mice and kidney tumours in male rats, yet there are apparently sound studies where these tumours were not seen. The situation with respect to mutagenicity is even worse, there is still uncertainty after 15 years of testing about the mutagenic potential of trichloroethylene. The assessment of both carcinogenic and mutagenic potential has been further confounded in the past by the use of mutagenic epoxide stabilisers in some commercial grades of trichloroethylene. In contrast to the animal toxicology, epidemiological studies of large groups of exposed workers have shown no evidence of an association between exposure to trichloroethylene and the 
occurrence of cancer in man. Recently, however, a study of a small population exposed to trichloroethylene has reported an increase in kidney cancer. This finding is apparently in conflict with those of the large cohort studies where no such increase was seen.

The uncertainty seen in the animal toxicology, and recently in the epidemiology studies, also extends to the classification of trichloroethylene around the world. In Europe, trichloroethylene is currently a category 3 carcinogen, in the USA (EPA), a B2 probable human carcinogen, $\cdot$ and in Japan a group $2 \mathrm{~B}$ carcinogen ${ }^{3)}$. Other organisations have classified trichloroethylene markedly differently; $\mathrm{ACGIH}^{2)}$ has placed trichloroehylene in their lowest category (5) whereas IARC $^{4}$ ) recently concluded that there is limited evidence of carcinogenicity in humans. In several cases quite different conclusions have been reached using essentially the same data set.

The confusion and lack of consistent response would perhaps suggest that more data is required to resolve these issues, yet in terms of conventional testing the data base is enormous and far exceeds that of many other chemicals. It is clear that trichloroethylene has the potential to cause cancer in animals. It is also clear that the way forward is to gain a greater understanding of the human relevance of the existing data rather than by further carcinogenicity or mutagenicity testing in animals. A number of mechanistic investigations of the major tumour types seen in animals have largely provided that understanding. This approach, which has proven successful in resolving many of the issues surrounding trichloroethylene, is the major topic of this review. A brief review of the more controversial epidemiology studies is also included since these studies are now the subject of a major debate, particularly in some European countries.

\section{Carcinogenicity}

Rodent cancer bioassays are frequently criticised because of high dose levels, lack of dose response data and the use of inappropriate strains of rats and mice. For most chemicals, a single two species cancer bioassay, accepting these weaknesses, is sufficient to establish the carcinogenic potential of a chemical. For trichloroethylene, there have been 18 cancer bioassays in which a single species/strain has been tested ${ }^{5}$. These studies have used 7 different strains of rat, 4 of mice and there has been a single study in hamsters. Duration and dose levels have varied considerably, and in many cases an inappropriate route of administration has been used; of the 18 bioassays, 11 administered the chemical by gavage in corn oil, a wholly inappropriate route for a volatile chemical. There have also been a number of bioassays of trichloroethylene metabolites in which the chemicals were administered in drinking water.

From these studies it is possible to draw a number of conclusions. The occurrence of an increased incidence of mouse liver tumours (hepatocellular carcinomas and adenomas) is the most frequently reported and significant observation $^{68}$. These tumours have been observed in both male and female Swiss and $B 6 C 3 F_{1}$ mice following exposure by either inhalation or gavage. Interestingly, increased incidences of liver tumours were not reported in other strains of mice (e.g. NMRI or (CR) ${ }^{9)}$ exposed to trichloroethylene, nor have they been reported in rats ${ }^{6-10)}$ or hamsters ${ }^{9}$.

Route of exposure has clearly influenced the outcome of the cancer bioassays. Increased incidences of lung tumours (adenocarcinomas) have been observed in female ICR mice ${ }^{10)}$ and female $\mathrm{B} 6 \mathrm{C} 3 \mathrm{~F}_{1}$ mice $^{6}$ exposed by inhalation. The effect was not observed in the Swiss mouse, nor in males of any of the mouse strains tested, nor in mice tested by the gavage route $e^{7-9)}$. This effect is also species specific and is not seen in rats or hamsters ${ }^{6,9,10)}$.

Small increased incidences of kidney tubular cell carcinomas have been seen in Sprague-Dawley, $F$ 344 and Osborne-Mendel rats ${ }^{6,8,11)}$ administered trichloroethylene. These findings were confined to males and no increased incidences were found in any of the other tested rat strains (ACI, August, Marshall and Wistar $)^{11)}$, although almost all rats exposed to high trichloroethylene levels had tubular cell cytokaryomegaly. The carcinogenicity results have in a number of cases been confounded by the reduced survival due to the nephrotoxic effect of excessive doses of trichloroethylene. However, although the incidences of these tumours were low and in many cases not significant, they have been the subject of further study because renal adenocarcinomas are extremely rare in control rats and recently, the same tumour type has been identified in a human epidemiology study.

Other isolated findings of increased tumour incidences have included Leydig cell tumours in male Sprague-Dawley rats following inhalation ${ }^{6}$, leukemia (mainly immunoblastic lymphosarcomas) in an inhalation study conducted in Sprague-Dawley rats $^{6)}$, and forestomach tumours in a gavage study with HA:ICR mice ${ }^{9)}$. These tumours are either increases in tumours normally found in high and variable incidences in control animals (leukemia, Leydig cell) or in the case of the forestomach tumours, may be explained by the presence of a 
mutagenic stabiliser (epichlorohydrin) in the test material. In the same study, a sample of trichloroethylene stabilised with 1,2-epoxybutane and a non-stabilised sample did not cause an increase in forestomach tumours.

Thus, all of the major tumour types seen following exposure of animals to trichloroethylene show species specificity (mouse liver and lung; rat kidney), some are sex specific (rat kidney; mouse lung), and others (mouse lung) are dependant upon the route of administration. This lack of consistent response, plus the uncertainty about the genotoxic potential of trichloroethylene has given rise to considerable uncertainty about the significance of these results for human health. Mechanistic explanations have been sought for each of these tumour types, the species specificity has been explained, and comparisons between rodents and humans have been made.

\section{Mutagenicity}

Although mutagenicity studies have been conducted on a routine basis for the last 15 years, many of them were not to the standards now recognised and accepted by health authorities or other relevant expert committees such as $\mathrm{OECD}^{12)}$. Hence a considerable number of unreliable and unconfirmed test results are found in the published literature. Equally a number of published studies are confounded by the use of test material of unknown purity or by the use of an industrial grade of the test material containing mutagenic stabilisers. It is not the purpose of this review to provide a detailed analysis of this database, such reviews are available in the literature ${ }^{5,13,14)}$. However, the issue of genotoxicity is a key component of any mechanistic assessment of a chemical carcinogen and must therefore be summarisd here.

Pure, unstabilised trichloroethylene is not mutagenic in bacteria and the majority of gene mutation assays in mammalian cells are also negative, although marginal increases have been reported in L5178Y lymphoma cells at concentrations approaching the limit of solubility of trichloroethylene. Trichloroethylene was not clastogenic in in vitro chromosomal aberration assays. Both positive and negative results have been reported in UDS studies, and weakly positive results have been seen in cell transformation assays. The purity of the trichloroethylene was not specified in any of these tests. Overall, pure trichloroethylene is non-mutagenic in the majority of in vitro tests. It is impossible to say whether the weak positive results, which were only seen at high dose levels, were influenced by the presence of matagenc stabilisers. In vivo, there are similarly conflicting results. For example, a positive result in a mouse bone marrow micronucleus assay is contradicted by two negative studies. Positive effects are seen in host mediated assays with yeast but not with Salmonella typhimurium. This pattern, which is common throughout these short-term tests fails to provide convincing evidence of genotoxicity but at the same time fails to entirely dismiss the possibility that trichloroethylene has a weak genotoxic potential under certain circumstances. Not surprisingly, understanding the mechanisms involved in the development of the animal tumours has probably given a better insight into the in vivo genotoxicity of trichloroethylene than has the short-term tests.

\section{Metabolism and pharmacokinetics}

Trichloroethylene is not a direct acting carcinogen and metabolism plays a key role in both the species differences and target organ carcinogenicity of trichloroethylene. An understanding of the metabolic pathways is therefore an essential part of the mechanisms of carcinogenicity.

Trichloroethylene is rapidly and extensively absorbed through the lungs and from the gastrointestinal tract. Following absorption it is widely distributed throughout the body via the systemic circulation. Highest concentrations are found in adipose tissues due to its high lipid solubility. Qualitatively, the metabolism of trichloroethylene is similar between species and sexes, the major metabolites in all species being trichloroethanol (as its glucuronide) and trichloroacetic acid (TCA). Trichloroethylene is rapidly metabolised by cytochrome $\mathrm{P} 4502 \mathrm{E}$, to a postulated epoxide intermediate which spontaneously rearranges to chloral (hydrate), which is in turn further metabolised to the major metabolites, trichloroethanol excreted mainly as its glucuronide, and trichloroacetic acid (Fig. 1) TCA is also reported to occur as glucuronide and coenzyme A conjugates. The rate of elimination of the major metabolites differs markedly. In rats and mice chloral and trichloroethanol are cleared from blood with a half-life of $1-2 \mathrm{~h}$ whereas the concentrations of TCA are sustained for up to $30 \mathrm{~h}$ after dosing. In humans, the half-life of trichloroacetic acid is approximately $52 \mathrm{~h}$ (range $35-70 \mathrm{~h}$ ). Unmetabolised trichloroethylene is eliminated by exhalation. A detailed review of the absorption, distribution, metabolism and elimination of trichloroethylene in animals and man has been published by Davidson and Beliles ${ }^{15)}$.

Minor metabolites of trichloroethylene include carbon dioxide, dichloroacetic acid (DCA), oxalic acid and $\mathrm{N}$-(hydroxyacetyl)-amino-ethanol ${ }^{16-19)}$. It 
Cytochrome P-450 - Major pathway

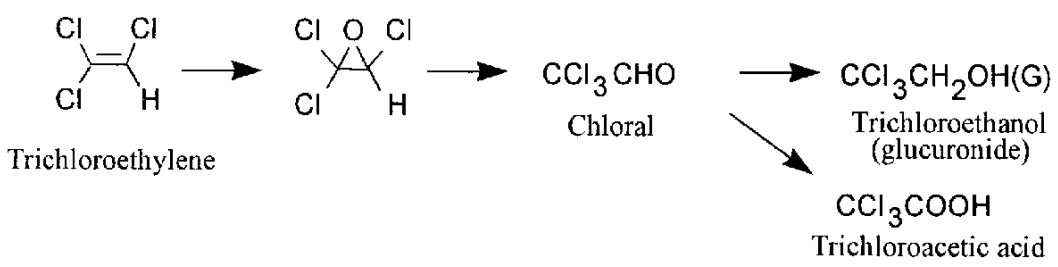

Minor metabolites: oxalic acid, N-(hydroxyacetyl)aminoethanol, dichloroacetic acid, carbon dioxide

Glutathione S-transferase - Minor pathway

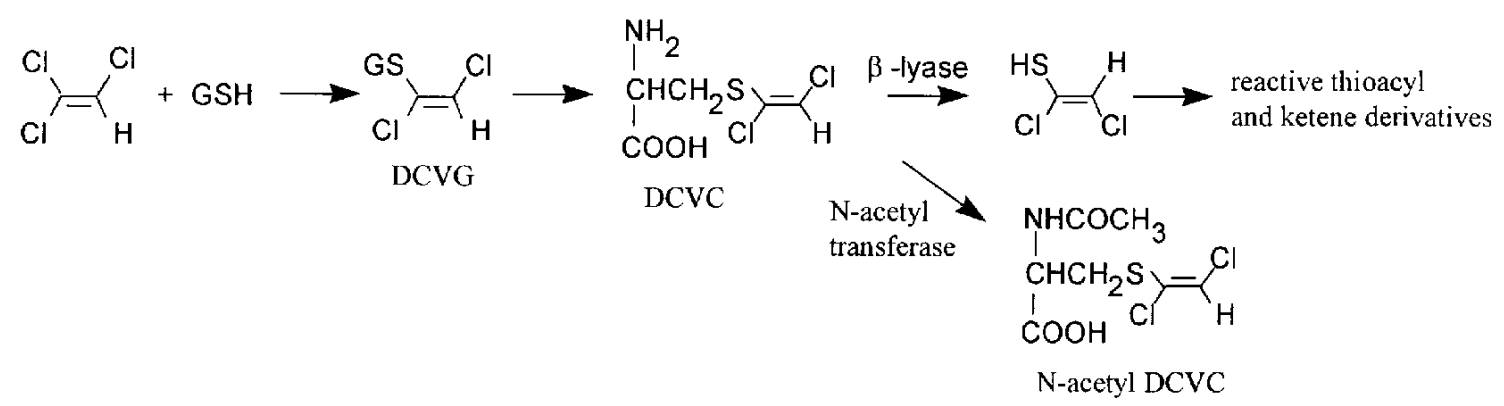

Fig. 1. The metabolism of trichloroethylene. DCVG: S-(1,2-dichlorovinyl) glutathione: DCVC: S-(1,2-dichlorovinyl)L-cysteine.

has been proposed that these metabolites are formed by hydrolysis of trichloroethylene epoxide although this has not been established experimentally. Similarly, the existence of the epoxide has not been confirmed in vivo and a number of authors have questioned the role of an epoxide in the metabolism of trichloroethylene ${ }^{19,20)}$. Miller and Guengerich ${ }^{20)}$ proposed a rearrangement of the initial oxidation product within the enzyme site which precluded the formation of an epoxide.

A second metabolic pathway involving conjugation of trichloroethylene with glutathione and metabolism through the mercapturic acid pathway has been discovered in recent years ${ }^{18,21-24)}$. Low levels of S-1,2-dichlorovinylglutathione have been detected in rat bile ${ }^{21)}$ and $\mathrm{S}-1,2$-dichlorovinyl-N-acetylcysteine $(0.01 \%$ of the dose $)$ in mouse and rat urine after dosing with trichloroethylene. The S(2,2-dichlorovinyl)- $\mathrm{N}$-acetylcysteine isomer was also detected in rat urine ${ }^{25}$. This pathway has also been described in humans, S- (1,2-dichlorovinyl) $-\mathrm{N}$ acetylcysteine being detected in the urine of workers exposed to trichloroethylene ${ }^{22)}$ and in the urine of volunteers exposed to trichloroethylene for $6 \mathrm{~h}^{23)}$.

Quantitatively, there are differences between species and strains with respect to the rate of oxidation of trichloroethylene and the relative yields and kinetic behaviour of its metabolites which ultimately impact on the carcinogenicity of this chemical (see below). In Swiss and $\mathrm{B}^{2} 3 \mathrm{~F}_{1}$ mice, TCA accounts for $7-12 \%$ of the dose ${ }^{16}$ whereas in NMRI mice this metabolite was only $0.1 \%$ of the dose $\mathrm{e}^{26)}$. The metabolic capacity of the mouse is also significantly greater than that of other species, cytochrome $\mathbf{P} 450$ metabolism of trichloroethylene being linear up to dose levels of $2 \mathrm{~g} / \mathrm{kgbw}^{27,28)}$, whereas in the rat this pathway is saturated at dose levels between 500 and $1,000 \mathrm{mg} / \mathrm{kgbw}^{27,29)}$. As a result, mice may be exposed to significantly higher concentrations of the major metabolites than are rats. Saturation of metabolism has not been established in man within the range of experimental studies (up to $380 \mathrm{ppm}$ ).

\section{Mechanisms of carcinogenicity}

The mono, di, tri and tetra-chloroethylenes all cause cancer in rodents to a greater or lesser degree and it was once assumed, based on structural similarities and similiar metabolic pathways, that there was a common mechanism. The established mechanism at the time was that for vinyl chloride (chloroethylene), which described the formation of a reactive epoxide and its interaction with DNA (see Green 1990 for a review ${ }^{30)}$ ). Although an epoxide is still assumed to be an intermediate in the metabolism of trichloroethylene, there is no evidence for its existence as a free chemical species and it is generally believed to exist only as a transition state within the cytochrome P450 enzyme 
complex ${ }^{20)}$. Certainly trichloroethylene does not have the genetic profile of vinyl chloride whose activity is attributed to an epoxide. Today, the mechanisms involved in development of liver and lung tumours in mice and kidney tumours in rats after exposure to trichloroethylene are largely understood and none of those mechanisms invokes a role for the epoxide. Surprisingly perhaps, the mechanisms in each target organ are different and must therefore be dealt with separately in this review.

\section{Mouse liver tumours}

A series of species specific responses are seen in the livers of mice following exposure to trichloroethylene. These responses, which are not seen in rats exposed under the same conditions, include organ growth, peroxisome proliferation, increased cell division and inhibition of cell-cell communication. These acute effects, which are seen with a significant number of other non-genotoxic carcinogens ${ }^{31)}$, are believed to be responsible for the tumours seen in mice exposed to trichloroethylene. Further support for this mechanism came from studies in which trichloroacetic acid, one of the major metabolites of trichloroethylene, was found to induce exactly the same responses and to cause liver tumours in mice at dose levels equivalent to the amount of TCA formed from trichloroethylene in vivo. The latter observation clearly precludes a role for the 'epoxide' in the development of these tumours and at the same time supports a nongenotoxic mechanism of carcinogenesis.

The lack of liver tumours in other species may be explained by kinetic differences and by differences in the way species respond to peroxisome proliferating chemicals. Neither peroxisome proliferation nor liver tumours are seen in rats exposed to trichloroethylene, even though trichloroethylene is metabolised to TCA in this species. The lack of response is due to saturation of trichloroethylene metabolism which limits the blood levels of TCA to below those required to induce peroxisome proliferation ${ }^{27,32)}$. In addition, the response of rats and mice to TCA itself also differs. Whereas both rats and mice show an increase in the number of peroxisomes when treated with TCA, there is a marked difference in cell division between the two species. Trichloroethylene (by inhalation or gavage) and TCA (in drinking water) cause marked increases in hepatic DNA synthesis and mitosis in mice $^{29,33,34)}$, but when TCA was administered to rats at equivalent dose levels in drinking water, Watson et al. found a marked reduction (to $10 \%$ of control) in DNA synthesis in rat liver ${ }^{35}$. This species difference in cell division appears to have a major impact on the carcinogenicity of TCA. When administered to rats and mice for a lifetime, an increase in liver cancer was seen in mice but not in rats $^{36-38)}$, suggesting that both peroxisome proliferation and cell devision are required for the subsequent development of liver tumours.

Similar species differences have been observed in studies investigating intercellular communication. Inhibition of gap-junction-mediated intercellular communication is a cellular effect exhibited by a number of non-genotoxic carcinogens and tumour promoters. Klauning et al ${ }^{39)}$ assessed the effects of trichloroethylene and its metabolites, TCA, tirchloroethanol and chloral hydrate on gapjunction-mediated intercellular communication in cultured $\mathrm{B}_{6} \mathrm{C} 3 \mathrm{~F}_{1}$ mouse and $\mathrm{F} 344$ rat hepatocytes. Trichloroethylene and TCA inhibited intercellular communication in both 24-h old and freshly plated mouse hepatocytes but not in rat hepatocytes. Trichloroethylene appeared to require cytochrome $\mathbf{P}$ 450 metabolism by the mouse hepatocytes since treatment with SKF-525A prevented the inhibition of intercellular communication by trichloroethylene. The inhibitory effect of TCA on intercellular communication was unaffected by treatment with SKF525A. While the species dependent effect of trichloroethylene on intercellular communication may be correlated with different rates and extent of metabolism of trichloroethylene by rat and mouse hepatocytes, the inhibiting effect of TCA only on mouse hepatocytes suggests that other intrinsic factors in the male mouse make this species more susceptible to the effects of trichloroethylene and TCA on gap junction mediated intercellular communication. These findings may account, in part, for the observed species difference in susceptibility to trichloroethylene induced liver carcinogenesis.

The relative roles of TCA and dichloroacetic acid (DCA) in the development of mouse liver tumours following exposure to trichloroethylene have been considered by a number of authors ${ }^{40-43)}$. Both metabolites have been shown to cause liver tumours when administered to $\mathrm{B} 6 \mathrm{C} 3 \mathrm{~F}_{1}$ mice in drinking water $^{36,37,44)}$, both induce peroxisome proliferation, are non-genotoxic, and appear to have a similar mode of action, although hepatotoxicity may play a role in the development of DCA induced tumours. Based on the analysis of urine from trichloroethylene treated rats and mice, DCA is a minor metabolite, less than $1 \%$ of the dose ${ }^{16,17)}$, and on this basis DCA was not considered to play a major role in the development of the mouse liver tumours whose formation was attributed to TCA, a major metabolite. However, studies at Washington State University ${ }^{41-43)}$ reported blood levels of DCA 
in mice exposed to trichloroethylene which were comparable to those from a carcinogenic dose of DCA, suggesting that DCA played a major role in the development of trichloroethylene induced mouse liver tumours. Furthermore, these authors reported higher blood levels of DCA in mice, than in rats exposed to trichloroethylene, further implicating a major role for DCA in the development of mouse specific liver tumours. Subsequently, it was shown that the apparently high levels of DCA in mouse blood had been produced from TCA during the analysis of blood for these metabolites, and that DCA was not in fact a major metabolite of trichlorothylene ${ }^{45)}$. Thus, although DCA is a known mouse liver carcinogen, the contribution of this minor metabolite to the development of liver tumours in mice exposed to trichloroethylene is probably minimal. The mechanism would be similar to that of TCA in that it would be a non-genotoxic one involving peroxisomes, cell division and possibly cytotoxicity.

The apparent strain differences between mice in the hepatocarcinogenicity of trichloroethylene may be explained by strain differences in metabolism to TCA. In Swiss and $\mathrm{B}^{6} \mathrm{C}_{3} \mathrm{~F}_{1}$ mice in which liver tumours are induced ${ }^{6-8)}$, TCA accounted for $7-12 \%$ of the dose ${ }^{16)}$, whereas in NMRI mice where liver tumours weres not induced ${ }^{9)}$, this metabolite account for only $0.1 \%$ of the dose ${ }^{26)}$.

In conclusion, there is strong evidence that the liver tumours seen in mice exposed to trichloroethylene are caused by a non-genotoxic mechanism based on the metabolism of trichloroethylene to TCA, stimulation of peroxisome proliferation, DNA synthesis, and inhibition of intercellular communication. Peroxisome proliferation is not seen in rats exposed to trichloroethylene because metabolism to TCA is limited by metabolic saturation. Furthemore, TCA, even at high dose levels, does not stimulate DNA synthesis or inhibit intercellular communication in the rat, nor is it a rat carcinogen. Thus, the mouse liver tumours are linked to a number of non-genotoxic responses which are mouse specific and do not occur in the rat.

Comparisons of the metabolism of trichloroethylene to TCA in rat, mouse and human hepatocytes confirmed the species differences between rats and mice seen in vivo and demonstrated that the rate of metabolism in human hepatocytes was significantly lower than that in the rat, and two orders of magnitude lower than that in mice ${ }^{32,46)}$. Furthermore, although peroxisome proliferation could be induced in vitro in rat and mouse hepatocytes by TCA, this metabolite, in common with other peroxisome proliferators ${ }^{31)}$, did not induce this response in human hepatocytes ${ }^{32,46)}$. Thus, in addition to quantitative differences in the rates of metabolism of trichloroethylene to TCA between mice and humans there are qualitative differences in the response of mouse and human liver cells to TCA. It is concluded therefore, that the liver tumours seen in Swiss and $\mathrm{B} \mathrm{C} 3 \mathrm{~F}_{1}$ mice exposed to trichloroethylene are caused by a combination of factors which are unique to these mice (Table 1) and consequently the mouse, in this instance, is considered to be an inappropriate animal model for human hazard assessment.

\section{Mouse lung tumours}

Trichloroethylene is a lung carcinogen in mice, but not rats, exposed by inhalation. As was the case in the liver, the mouse lung appears to be uniquely sensitive to this chemical, and once again, mechanistic studies have provided an explanation for that sensitivity and facilitated a human hazard assessment. Inhaled trichloroethylene has been shown to be cytotoxic to the Clara cells of the mouse bronchiolar epithelium ${ }^{47-50}$ ). The effect is specific to the Clara cell, no damage being apparent to other cell types in the lung, nor is the response seen in the rat at equivalent dose levels. The possible significance of these findings for tumour development in mice has been examined in a series of invivo and in-vitro studies reported by Odum et al..$^{50)}$ and Green et al. ${ }^{51)}$ The Clara cell toxicity, which is characterised by hydropic vacuolation of the

Table 1. A summary of the effects of Trichloroethylene (TRI) and its metabolite trichloroacetic acid (TCA) on mouse, rat and human liver. The references for the data in this table are given in the text

\begin{tabular}{lccccccccc}
\hline Species & $\begin{array}{c}\text { Metabolism of } \\
\text { trichloroethylene to } \\
\text { TCA }\end{array}$ & \multicolumn{2}{c}{$\begin{array}{c}\text { Peroxisome } \\
\text { proliferation } \\
\text { TRI }\end{array}$} & \multicolumn{2}{c}{ TCA } & DNA & \multicolumn{2}{c}{ Cell-cell } & \multicolumn{2}{c}{ Cancer } \\
synthesis & TRI TCA & TRI & TCA & TRI & TCA \\
\hline Mouse & ++++ & + & + & + & + & + & + & + & + \\
Rat & -+ & - & + & - & - & - & - & - & - \\
Human & + & - & - & ND & ND & ND & ND & - & - \\
\hline
\end{tabular}

a mouse and rat data measured in vivo and in hepatocytes in vitro; human data measured in hepatocytes in vitro. ND. Not determined. 
smooth endoplasmic reticulum, was observed in female CD-1 mice exposed for a single six hour period to trichloroethylene at concentrations ranging from 20 to $2,000 \mathrm{ppm}$ (tumours were seen following lifetime exposure to $450 \mathrm{ppm}^{10)}$ ). The effects were dose-related, with very few cells affected at 20 ppm whereas most Clara cells were affected at exposures of $200 \mathrm{ppm}$ and above. During a typical cancer bioassay exposure regime of $6 \mathrm{~h}$ day, 5 days per week, the Clara cell lesion resolved after 5 days of repeated exposure (to $450 \mathrm{ppm}$ ), but re-occurred after the first exposure of the following week ${ }^{50)}$. Marked increases in cell division were seen in the bronchiolar epithelium at the end of each week of exposure establishing a weekly cycle of cell damage and cell proliferation ${ }^{51)}$.

A mechanism to explain the development of the Clara cell lesion has been put forward by Odum et $a l .^{50)}$ Metabolism studies using isolated mouse lung Clara cells in vitro showed that a similar metabolic pathway for trichloroethylene existed to that known in the liver, ie. via chloral to trichloroethanol and TCA. Trichloroethanol is conjugated in the liver with glucuronic acid to form the major metabolite of trichloroethylene, approximately $80-90 \%$ of total metabolism. However, in Clara cells the metabolism of chloral to trichloroethanol by alcohol dehydrogenases was reduced, and the conjugation of trichloroethanol by UDP glucuronyl transferases was virtually absent. As a result, chloral accumulated in the Clara cell causing cellular damage (Fig. 2). When tested in vivo, chloral was the only trichloroethylene metabolite to cause the mouse lung Clara cell lesion, trichloroethanol and TCA having no effect.

Comparisons of the ability of mouse, rat and human lung to metabolise trichloroethylene to chloral found high rates in the mouse, significantly lower rates in the rat, and no detectable rate in human lung ${ }^{51)}$. Furthermore, the cytochrome P450 isoenzyme responsible for this metabolic step ( $P$ 4502E1) could not be detected in human lung homogenates by western blotting or in human lung sections with an antibody. These findings are consistent with reports that human lungs contain very few Clara cells and that those cells show no smooth endoplasmic reticulum ${ }^{52)}$, the membranes where the cytochrome $\mathbf{P} 450$ enzymes are principally located.

In conclusion, the repetitive damage and cell division which occurs specifically in the mouse lung Clara cell on exposure to trichloroethylene is believed to be the primary cause of the lung tumours seen in mice. Exactly the same effects have been seen with methylene chloride, another mouse specific lung carcinogen, thus providing further support for this conclusion. As was the case in the

Mouse Liver

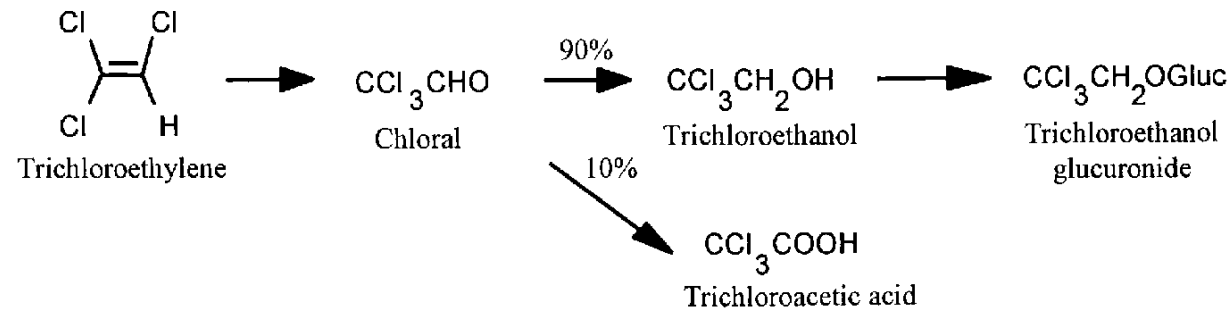

Mouse Lung Clara Cells

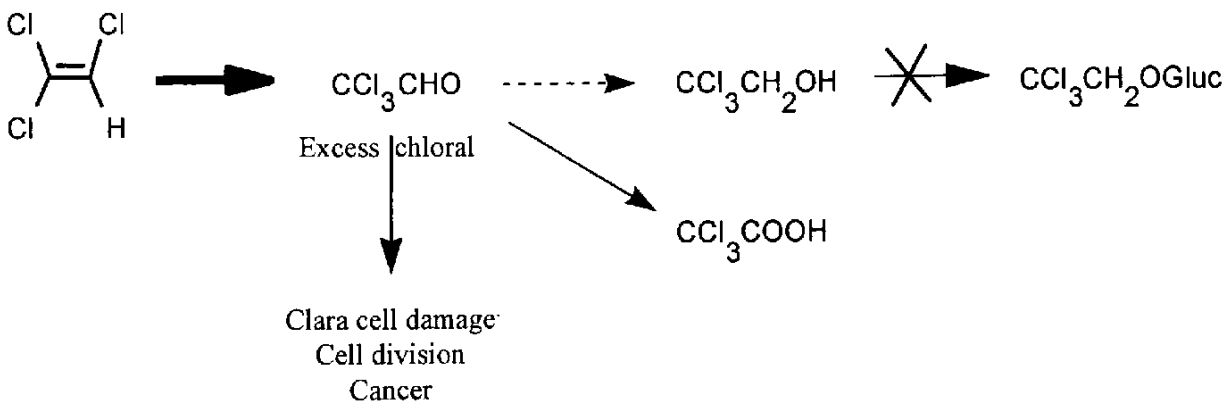

Fig. 2. A comparison of the metabolism of trichloroethylene in mouse liver and mouse lung Clara cells, in relation to the development of mouse lung tumours. 
liver, the mouse lung is unique in its response to trichloroethylene. Clara cell damage and lung cancer are not seen in rats and on the basis that there is no detectable metabolism of trichloroethylene in the human lung, the present author concludes that trichloroethylene exposure does not cause lung cancer in humans by this mechanism.

\section{Rat kidney tumours}

Trichloroethylene has caused low, but significant, incidences of renal tumours in several lifetime studies in which rats were exposed either by gavage or by inhalation ${ }^{6,8,11}$. Some of the studies were judged inadequate because of poor survival as a result of nephrotoxicity and in one study kidney tumours were seen but did not reach statistical significance $^{11)}$. In yet further studies kidney tumours were not seen in rats $^{9,10)}$, nor have kidney tumours been reported in mice in any of the studies. Nephrotoxicity has been reported in all of the lifetime studies in both rats and mice.

A number of potential mechanisms, have been investigated to explain trichloroethylene induced rat specific renal tumours. Protein droplet nephropathy, a response associated with a number of male rat specific renal carcinogens, was not seen in male rats given high doses of trichloroethylene $(2,000 \mathrm{mg} /$ kgbw), daily for up to 42 days $^{24,53)}$. The cytotoxicity which is seen in all of the long-term studies does appears to be a major factor, renal tumours not having been seen in the absence of significant nephrotoxicity. A further mechanism has been put forward following the discovery that trichloroethylene is metabolised by conjugation with glutathione $^{18,{ }^{54)}}$ (for a review see Goeptar et al. ${ }^{54)}$ ). This pathway, which produces S-(1,2-dichlorovinyl)L-cysteine (DCVC), a known bacterial mutagen and nephrotoxin as an intermediate ${ }^{56)}$, has been quantified in rats, mice and humans in vivo ${ }^{18,22} 24,55$, and in liver and kidney fractions in vitro ${ }^{24,57}$. The effects of trichloroethylene and DCVC on the kidney have also been compared in vivo ${ }^{24,58,59)}$.

The discovery of this pathway in humans ${ }^{22,}{ }^{23)}$, together with an increased incidence of kidney cancer in a small population occupationally exposed to trichloroethylene ${ }^{54)}$, has led some authors to conclude that a common mechanism, based on the formation of DCVC, operates in both rats and humans ${ }^{54)}$. However, a more detailed appraisal of the data available to-date does not fully support this assumption.

Metabolism of trichloroethylene by the glutathione pathway occurs to a very minor extent in rats, mice and humans, typically $<0.01 \%$ of the dose being excreted in urine as $\mathrm{N}$-acetyl-S- $(1,2-$ dichlorovinyl) cysteine, the ultimate metabolite of this pathway ${ }^{18,22-25}$. Based on measurements of this metabolite, the pathway occurs to a greater extent in mice than rats $^{22}$, and in a human volunteer study the levels of N-acetyl-S-(1,2-dichlorovinyl) cysteine were significantly lower than those in rats exposed simultaneously ${ }^{23)}$. Comparisons in vitro of the rate of conjugation of trichloroethylene with glutathione in the liver, or of the activities of $\beta$ lyase and $\mathrm{N}$-acetyl transferase in the kidney, similarly failed to provide evidence to explain the species specificity of the trichloroethylene-induced rat kidney tumours ${ }^{24}$. In vivo, three acute studies have concluded that the mouse is more sensitive to the nephrotoxic effects of both trichloroethylene and DCVC that the rat ${ }^{24,58,59)}$. The potency of DCVC in these studies and in long-term dosing studies ${ }^{60,61)}$ questions whether the very small amounts of DCVC formed from trichloroethylene would be either nephrotoxic nor carcinogenic. Thus, at the present time, this metabolic pathway does not provide a satisfactory explanation for the rat specific tumours.

Although there is a poor correlation between metabolism by the glutathione pathway and the development of these tumours it is generally accepted that the tumours are linked to the nephrotoxicity seen in all of the bioassays. The kidney tumours have not been seen in the absence of damage and at the present time renal damage appears to the most reliable indicator of risk. Interestingly, trichloroethylene is a very weak acute nephrotoxin in the rat, doses of up to $1,000 \mathrm{mg} / \mathrm{kg}$, daily for 10 days, having no detectable effect on the kidney $^{24,29,62)}$. It is evident therefore, that both prolonged and high exposure to trichloroethylene are required to induce kidney damage, and cancer in rats.

Evidence of renal toxicity in human exposed chronically to trichloroethylene is limited, despite the fact that reports of toxicity in other organs, for example in the liver, indicate that substantial exposure has occurred in the past. Seldén et al. ${ }^{63)}$ failed to find evidence for kidney damage in a group exposed occupationally to $50 \mathrm{mg} / \mathrm{m}^{3}$ trichloroethylene. Bruning et al. ${ }^{64)}$ reported limited evidence of chronic tubular damage in cases of renal cell cancer which developed after long and high exposure to trichloroethylene. The incidence of damage, assessed by the excretion of urinary proteins, was higher in the trichloroethylene exposed group than in a group of renal cell cancer patients without exposure to trichloroethylene. Exposure data was not available other than from anecdotal reports of pre-narcotic symptoms which suggested 
Table 2. Cohort studies of workers occupationally exposed to trichloroethylene

\begin{tabular}{|c|c|c|c|c|c|}
\hline \multirow[t]{2}{*}{ Cohort size } & \multirow{2}{*}{$\begin{array}{l}\text { Period of } \\
\text { potential } \\
\text { exposure }\end{array}$} & \multicolumn{2}{|c|}{ Exposure level (ppm) } & \multirow{2}{*}{$\begin{array}{c}\text { Follow-up } \\
\text { period } \\
\text { (yrs) }\end{array}$} & \multirow[t]{2}{*}{ Reference } \\
\hline & & TWA $^{\mathrm{a}}$ & Maximum & & \\
\hline 3,089 & $1965-1992$ & $<50$ & $>500^{b}$ & 26 & Antilla $e t a l{ }^{65)}$ \\
\hline 2,646 & $1957-1983$ & $\begin{array}{c}\text { Not } \\
\text { specified }\end{array}$ & $\begin{array}{c}\text { Not } \\
\text { specified }\end{array}$ & 27 & $\begin{array}{l}\text { Shindell and } \\
\text { Ulrich }\end{array}$ \\
\hline 4,733 & $1950-1986$ & $<50$ & $>50$ & 36 & $\begin{array}{l}\text { Wong and } \\
\text { Morgan }{ }^{677}\end{array}$ \\
\hline 6,929 & $1952-1979$ & $\begin{array}{c}\text { Not } \\
\text { specified }\end{array}$ & $600^{c}$ & 30 & Spirtas et al. ${ }^{68)}$ \\
\hline 1,670 & $1950-1979$ & $<20$ & $>40$ & $\begin{array}{c}\text { Mortality : } \\
37 \\
\text { Morbidity : } \\
38\end{array}$ & Axelson $e t a l .{ }^{69)}$ \\
\hline
\end{tabular}

the exposures were very high. The authors claim that the findings support the hypothesis that chronic tubular damage is a necessary precondition for trichloroethylene to exert its nephrocarcinogenic effects.

In conclusion, the mechanism by which trichloroethylene causes a low incidence of rat kidney tumours remains uncertain. At the present time, the most acceptable explanation for these tumours, and the one on which there is general agreement, is that invoking sustained chronic toxicity. It is clear from both the rat and human studies that both high and prolonged exposure to trichloroethylene are required to cause kidney damage and it follows that humans occupationally exposed to trichloroethylene at low levels, where there is no evidence of kidney damage, will not be at risk.

Equally, there is uncertainty as to whether trichloroethylene exposure has caused an increase in human kidney cancer. The 'common mechanism,' that involving glutathione conjugation of trichloroethylene and the formation of DCVC, which has been put forward as an explanation for both rat and human tumours has yet to be proven, there being significant concerns over the species specificity and toxicological significance of this very minor metabolic pathway.

\section{Epidemiology studies}

There have been a number of large well conducted epidemiology studies of occupational groups exposed to trichloroethylene (Table 2; see ECETOC ${ }^{5}$ ) for review). In almost all cases exposures were known either from hygiene measurements or from biological monitoring of trichloroacetic acid in urine. Taken together, the five cohort studies ${ }^{65-69}$ ) have reported on 19,087 workers with follow-up of more than 25 years for four of the studies. All of the studies investigated mortality and the Axelson et al. study $^{69)}$ also reports on cancer incidence. None of the studies demonstrated a link between exposure to trichloroethylene and an increased risk for cancer in general or for any specific type of cancer. In addition to the large cohort studies shown in Table 2, there have been two uncontrolled liver cancer case studies ${ }^{70,71)}$, one uncontrolled small cohort study ${ }^{72)}$, and one colon cancer case control $^{73)}$. Again, none of these studies demonstrated a link between exposure and an increase in cancer mortality or excess incidence of liver or colon cancer.

It is perhaps surprising in view of the outcome of the large cohort studies that a study of a small population of 169 workers exposed to trichloroethylene in a cardboard factory should reveal a markedly increased incidence of renal cancer ${ }^{54}$. Five cases of kidney cancer were found in the study and no cases in the control group leading the authors to conclude a strong casual relationship between exposure to trichloroethylene and renal cell tumours. This conclusion is questionable for several reasons. Firstly, the study was initiated because of a priory concern raised by a cluster of renal cancer cases in this population. Secondly, although exposure was poorly characterised, it is clear that there is no dose relationship with exposure to trichloroethylene, three of the renal cancer cases working in jobs with low exposure. Finally, the biologically plausible mechanism underlying these findings is not supported by recent investigations (see Mechanisms Section above).

Recently a working group of the International Agency for Research on Cancer (IARC February 1996) concluded that there was limited evidence, 
when considering the larger cohort studies together, of a link between trichloroethylene exposure and cancer. A positive association was observed between exposure and liver, biliary and non-Hodgkin's lymphoma. The increases within individual studies were, however, not significant except for cervical cancer which was dismissed by the working party as being casual and due to bias from socioeconomic status. It is not clear why the more modest increases in liver, biliary and non-Hodgkin's lymphoma were considered to be a basis for 'limited evidence."

\section{Human hazard assessment}

The major findings in the rodent cancer bioassays have been of liver and lung tumours in mice. The mechanisms involved in the development of these tumours have been elucidated and are clearly specific to mice, not in one single aspect, but in all. For example, peroxisome proliferation is seen only in mice, a direct consequence of the high metabolic capacity of this species and the resulting blood levels of trichloroacetic acid. Similarly increases in cell division and inhibition of cell-cell communication are also mouse specific phenomena. Rats are protected from peroxisome proliferation by saturable metabolism and lower blood levels of TCA, and they also fail to undergo hepatic cell division following dosing with TCA. Humans are similarly protected by lower blood levels of TCA and the fact that human liver is refractory to peroxisome proliferators in general $^{31}$, and in this case, TCA specifically. Thus, based either on metabolic comparisons or on the physiological responses of the liver to trichloroethylene and TCA, the mouse is unique and there is good evidence that, for trichlorocthylene, the mouse is not a good model for humans. These tumours should not therefore be used as the basis of a human hazard assessment.

The same is equally true for the mouse lung tumours. A set of circumstances, again unique to the mouse, results in the species specific tumours seen in this organ. Exceptionally high cytochrome P450 metabolism in Clara cells coupled with a block at the end of the metabolic pathway results in an accumulation of chloral, cellular damage and cell division. This is further exacerbated by the design of rodent cancer bioassays which results in a cycle of cell damage and cell division during each of the first weeks of the bioassay. The abnormal metabolic profile does not occur in mouse liver, in rat liver or lung, and the absence of cytochrome P4502E1 in human lung suggests that it could not occur there either.

The development of rat kidney tumours has at present has been attributed to long term kidney damage rather than to a specific molecular mechanism. The incidences of kidney cancer seen in the rat are extremely low, they have only been seen at or above a maximum tolerated dose, and in many cases the incidences seen have been dismissed because of poor survival due to kidney damage. There is a general agreement in the literature that these tumours will not occur in the absence of kidney damage and it is encouraging from a human health point of view that even in the rat, long term exposure to high concentrations of trichloroethylene is required to induce kidney damage. It seems highly unlikely therefore that at current occupational levels, trichloroethylene will be nephrotoxic, indeed there is evidence to show that it is not.

In conclusion, there is good evidence to suggest that the mechanisms of carcinogenicity identified in animals will not operate in humans. The large well conducted cohort studies of exposed human populations, which have failed to demonstrate a link between exposure to trichloroethylene and an increased risk for cancer in general, or for any specific type of cancer, support this conclusion. Thus, although both the animal toxicology and the human epidemiology of trichloroethylene remain areas of debate and active research, it seems unlikely that these conclusions will change.

Acknowledgment: The author would like to thank Dr Louis Bloemen of Dow Benelux for his guidance with the section on epidemiology.

\section{References}

1) IARC Monographs on the evaluation of the carcinogenic risk of chemicals to humans, Vol. 20, Some halogenated hydrocarbons. Lyon: International Agency for Research on Cancer, 1979: 545-572.

2) ACGIH (American Conference of Govermental Industrial Hygienists). Trichloroethylene. Notice of intended change. Appl Occup Environ Hyg 1992; 7 : 786-791.

3) Japan Society for Occupational Health. Recommendation of occupational exposure limits (1996-1997). J Occup Health 1996; 38: 134-147.

4) IARC Monographs on the evaluation of the carcinogenic risk to humans, Vol. 63, Dry cleaning, some chlorinated solvents and other industrial chemicals. Lyon: International Agency for Research on Cancer, 1995: 95-158.

5) ECETOC. Trichloroethylene: Assessment of human carcinogenic hazard. Technical Report No. 60. Brussels: ECETOC, 1994.

6) Maltoni C, Lefemine G, Cotti G, Perino G. Longterm carcinogenicity bioassays on trichloroethylene administered by inhalation to Sprague-Dawley rats 
and Swiss and $\mathrm{B} \mathrm{C} 3 \mathrm{~F}_{1}$ mice. Ann NY Acad Sci $1988 ; 534: 316-342$.

7) National Cancer Institute. Carcinogenesis bioassay of trichloroethylene CAS No. 79-01-6. National cancer institute technical report series No. 2. DHEW (NIH) Pub. 76-802; NTIS Pub. No PB-264122. Springfield, VA: National Technical Information Service, 1976.

8) NTP. National Toxicology Program Carcinogenesis bioassays of trichloroethylene in F344 rats and B6C3F $_{1}$ mice. U.S. Dept. of Health and Human Services, NIH Publication No. 82-1799, 1983.

9) Henschler D, Romen W, Elsasser HM, Reichert D, Eder E, Radwan Z. Carcinogenicity study of trichloroethylene by long term inhalation in three animal species. Arch Toxicol 1980; 43: 237-248.

10) Fukuda $\mathbf{K}$, Takemoto $K$, Tsurata $H$. Inhalation carcinogenicity of trichloroethylene in mice and rats. Ind Health $1983 ; 21: 243-254$.

11) National Toxicology Program. NTP technical report on the toxicology and carcinogenesis studies of trichloroethylene in four strains of rats. NTP TR 273, April 1988: 22.

12) OECD (Organisation for Economic Co-operation and Develpment). Guidelines for the testing of chemicals 2, guidelines Paris: OECD, 1993: 471-485.

13) Crebelli $R$, Carere A. Genetic toxicology of 1,1,2trichloroethylene. Mutation Research 1989; 221: 1137.

14) Fahrig R, Madle S, Baumann H. Genetic toxicology of trichloroethylene. Mutation Research 1995; 340 : $1-36$.

15) Davidson IWF, Beliles RP. Consideration of the target organ toxicity of trichloroethylene in terms of metabolite toxicity and pharmaco-kinetics. Drug Metabolism Reviews, 1992; 23 ( 5 \& 6) : 493-599.

16) Green T, Prout MS. Species differences in response to trichloroethylene. II. Biotransformation in rats and mice. Toxicol Appl Pharmacol 1985; 79: 401411.

17) Dekant W, Schulz A, Meztlerm M, Henschler D. Absorption, elimination, and metabolism of trichloroethylene: a quantitative comparison between rats and mice. Xenobiotica 1986;16:143-152.

18) Dekant W, Metzler M, Henschler D. Identification of S-1, 2-dichlorovinyl-N-acetyl cysteine as a urinary metabolite of trichloroethylene: a possible explanation for its nephrocarcinogenicity in male rats. Biochem Pharmacol 1986; 35: 2455-2458.

19) Bruckner JV, Davis BD, Blancato JN. Metabolism, toxicity, and carcinogenicity of trichloroethylene. CRC Critical Reviews in Toxicology, 1989; 20:3150.

20) Miller RE, Guengerich FP. Oxidation of trichloroethylene by liver microsomal cytochrome P-450: evidence for chlorine migration in a transition state not involving trichloroethylene oxide. Biochemistry 1982; 21 : 1090-1097.

21) Dekant W, Koob M, Henschler D. Metabolism of trichloroethylene-in vivo and in vitro evidence for ac- tivation by glutathione conjugation. Chem Biol Interactions $1990 ; 73$ : 89-101.

22) Birner G, Vamvakas S, Dekant W, Henschler D. The nephrotoxic and genotoxic $\mathrm{N}$-acetyl-S-dichlorovinylL-cysteine is a urinary metabolite after occupational 1,1,2-trichloroethylene exposure in humans: implications for the risk of trichloroethylene exposure. Environ Health Perspect 1993; 99 : 281-284.

23) Birnauer U, Birner G, Dekant W, Henschler D. Biotransformation of trichloroethylene: dose dependant excretion of 2,2,2-trichloro-metabolites and mercapturic acids in rats and humans after inhalation. Arch Toxicol 1996; 70: 338-346.

24) Green T, Dow J, Ellis MK, Foster JR, Odum J. The role of glutathione conjugation in the development of kidney tumours in rats exposed to trichloroethylene. Chem Biol Interactions 1997; 105: 99-117.

25) Commandeur JNM, Vermeulen NPE. Identification of $\mathrm{N}$-acetyl-S-(2,2-dichlorovinyl)-L-cysteine and $\mathrm{N}$ acetyl-S-(1,2-dichlorovinyl)-L-cysteine as two mercapturic acids of trichloroethylene in the rat. Chemical Research in Toxicology 1990; 3: 212-218.

26) Dekant W, Metzler M, Henschler D, Novel metabolites of trichloroethylene through dechlorination reactions in rats, mice and humans. Biochemical Pharmacology 1984; 33: 2021-2027.

27) Prout MS, Provan WM, Green T. Species differences in response to trichloroethylene, I. Pharmacokinetics in rats and mice. Toxicol Appl Pharmacol 1985; 79: 389-400.

28) Buben JA, O'Flaherty EJ. Delineation of the role of metabolism in the hepatotoxicity of trichloroethylene and perchloroethylene: A dose-effect study. Toxicol Appl Pharmacol 1985; 78: 105-122.

29) Stott WT, Quast JF, Watanabe PG. The pharmacokinetics and macromolecular interactions of trichloroethylene in mice and rats. Toxicol Appl Pharmacol 1982; 62: 137-151.

30) Green T. Chloroethylenes: A mechanistic approach to human risk evaluation. Annu Rev Pharmacol Toxicol 1990; 30: 73-89.

31) Ashby JA, Brady A, Elcombe CR, et al. Mechanistically-based human hazard assessment of peroxisome proliferator-induced hepatocarcinogenesis. Human Experimental Toxicol 1994; 13: 1-117.

32) Elcombe CR. Species differences in carcinogenicity and peroxisome proliferation due to trichloroethylene. A biochemical human hazard assessment. Arch Toxicol Suppl 1985; 8:6-17.

33) Mirsalis JC, Tyson CK, Loh EN, et al. Induction of hepatic cell proliferation and unscheduled DNA synthesis in mouse hepatocytes following in vivo treatment. Carcinogenesis $1985 ; 6: 1521-1524$.

34) Dees $C$, Travis $C$. The mitogenic potential of trichloroethylene in $\mathrm{B}_{6} \mathrm{C} 3 \mathrm{~F}_{1}$ mice. Toxicology Letters 1993; 69: 129-137.

35) Watson SC, Foster JR, Elcombe CR. Trichloroacetic acid: species difference in the stimulation of hepatic DNA synthesis. Human Exptl Toxicol 1993; $12: 577$.

36) Herren-Freund SL, Pereira MA, Khoury MD, Olson 
G. The carcinogenicity of trichloroethylene and its metabolites, trichloroacetic acid and dichloroacetic acid, in mouse liver. Toxicol Appl Pharmacol 1987; 90: 183-189.

37) DeAngelo AB, Daniel FB, Stober JA, Olson GR. The carcinogenicity of dichloroacetic acid in the male B6C3F 1 mouse. Fund Appl Toxicol 1991; 16: 337-347.

38) DeAngelo AB, Daniel FB. An evaluation of the carcinogenicity of the chloroacetic acids in the male F344 rat. Toxicologist 1992; 12: 756 [abstract ${ }_{\text {- }}$.

39) Klaunig JE, Ruch RJ, Lin EL. Effects of trichloroethylene and its metabolites on rodent hepatocyte intercellular communication. Toxicol Appl Pharmacol 1989; 99 : 454-465.

40) Larson JL, Bull RJ. Metabolism and lipoperoxidative activity of trichloroacetate and dichloroacetate in rats and mice. Toxicol Appl Pharmacol 1992; 115 : $268-277$.

41) Larson JL, Bull RJ. Species differences in the metabolism of trichloroethylene to the carcinogenic metabolites trichloroacetate and dichloroacetate. Toxicol Appl Pharmacol 1992; 115: 278-285.

42) Templin MV, Parker JC, Bull RJ. Relative formation of dichloroacetate and trichloroacetate from trichloroethylene in male $\mathrm{B}_{6} \mathrm{C} 3 \mathrm{~F}_{1}$ mice. Toxicol Appl Pharmacol 1993, 123: 1-8.

43) Bull RJ, Templin M, Larson JL, Stevens DK. The role of dichloroacetate in the hepato-carcinogenicity of trichloroethylene. Toxicology Letters 1993; 68: 203-211.

44) Bull RJ, Sanchez IM, Nelson MA, Larson JL, Lansing $\mathrm{AJ}$. Liver tumor induction in $\mathbf{B} 6 \mathbf{C} 3 \mathbf{F}_{1}$ mice by dichloroacetate and trichloroacetate. Toxicology 1990; 63 : 341-359.

45) Ketcha MM, Stevens DK, Warren DA, Bishop CT, Brashear WT. Conversion of trichloroacetic acid to dichloroacetic acid in biological samples. J Anal Toxicol 1996; 20: 236-241.

46) Knadle SA, Green CE, Baugh $M$, et al. Trichlorocthylene biotransformation in human and rat primary hepatocytes. Toxicology In Vitro 1990; 4: 537-541.

47) Forkert PG, Sylvestre PL, Poland JS. Lung injury indued by trichloroethylene. Toxicol $1985 ; 34: 143-$ 160.

48) Forkert PG, Birch DW. Pulmonary toxicity of trichloroethylene in mice. Covalent binding and morphological manifestations. Drug Metab Dispos 1989; 17: 106-113.

49) Villaschi S, Giovanetti A, Lombardi CC, Nicolai G, Garbati M, Andreozzi U. Damage and repair of mouse bronchial epithelium following acute inhalation of trichloroethylene. Experimental Lung Research $1991 ; 15: 601-614$.

50) Odum J, Foster JR, Green T. A mechanism for the development of Clara cell lesions in the mouse lung after exposure to tirchloroethylene. Chem Biol Interactions $1992 ; 83: 135-153$.

51) Green T, Mainwaring GW, Foster JR. Trichloro- ethylene induced mouse lung tumours: Studies of the mode of action and comparisons between species. Fund Appl Toxicol 1997; 37 : 125-130.

52) Smith MN, Greenberg SD, Spjut HJ. The Clara cell: A comparative ultrastructural study in mammals. Am J Anatomy 1979; 155: 15-30.

53) Goldsworthy TL, Popp JA. Chlorinated hydrocarbon-induced peroxisomal enzyme activity in relation to species and organ carcinogenicity. Toxicol Appl Pharmacol 1987; 88: 225-233.

54) Henschler D, Vamvakas S, Lammert $S$, et al. Increased incidence of renal cell tumours in a cohort of cardboard workers exposed to trichloroethylene. Arch Toxicol 1995; 69: 291-299.

55) Goeptar AR, Commandeur JNM, van Ommen B, van Bladeren PJ, Vermeulen NPE. Metabolism and kinetics of trichloroethylene in relation to toxicity and carcinogenicity. Relevance of the mercapturic acid pathway. Chem Res Toxicol 1995; 8: 3-21.

56) Green T, Odum J. Structure/activity studies of the nephrotoxic and mutagenic action of cysteine conjugates of chloro and fluoralkenes. Chem Biol Interact $1985 ; 54: 15-31$.

57) Lash HL, Xu Y, Elfarra AA, Duescher RJ, Parker JC. Glutathione dependant metabolism of trichloroethylene in isolated liver and kidney cells of rats and its role in mitochondrial and cellular toxicity. Drug Metab Dispos 1995; 23: 846-853.

58) Eyre RJ, Stevens DK, Parker JC, Bull RJ. Acidlabile adducts to protein can be used as indicators of the cysteine S-conjugate pathway of trichloroethylene metabolism. J Toxicol-Environ-Health 1995 ; 46: 443464.

59) Eyre RJ, Stevens DK, Parker JC, Bull RJ. Renal activation of trichloroethylene and $\mathrm{S}$-(1,2-dichlorovinyl)-L-cysteine and cell proliferative responses in the kidneys of $\mathrm{F} 344$ rats and $\mathrm{B} 6 \mathrm{C} 3 \mathrm{~F}_{\mathrm{l}}$ mice. JToxicol-Environ-Health $1995 ; 46: 465-481$.

60) Terracini B, Parker VH. A pathological study on the toxicity of S-dichlorovinyl-L-cysteine. Food Cosmet Toxicol 1965; 3: 67-74.

61) Jaffe DR, Gandolfi AJ, Nagle RB. Chronic toxicity of $\mathrm{S}$-(trans-1,2-dichlorovinyl)-L-cysteine in mice. $\mathrm{J}$ Applied Toxicol 1984; $4:$ 315-319.

62) Goldsworthy TL, Lyght O, Burnett VL, Popp JA. Potential role of a-2u-Globulin, protein droplet accumulation, and cell replication in the renal carcinogenicity of rats exposed to trichloroethylene, perchloroethylene, and pentachloroethane. Toxicol Appl Pharmacol 1988; 96: 367-379.

63) Seldén A, Hultberg B, Ulander A, Ahlborg G Jr. Trichloroethylene exposure in vapour degreasing and the urinary excretion of N-acetyl-b-D-glucosaminidase. Arch Toxicol 1993; 67: 224-226.

64) Bruning T, Golka K, Makropoulos V, Bolt HM. Preexistence of chronic tubular damage in cases of renal cell cancer after high and long exposure to trichloroethylene. Arch Toxicol 1996; 70: 259-260.

65) Antilla A, Pukkala E, Sallmen M, Hernberg S, Hemminki K. Cancer indidence among Finnish 
workers exposed to halogenated hydrocarbons. J Occup Environm Health 1995; 37: 797-806.

66) Shindell S, Ulrich S. A cohort study of employees of a manufacturing plant using trichloroethylene. J Occup Med 1985; $27: 577-579$.

67) Wong O, Morgan R. 1990. Historical prospective mortality study of Hughes Aireraft emphoyees at air force plant \#44. ENSR Health Sciences, Document 4700-042-001, Alameda, CA.

68) Spirtas R, Stewart P, Lee S. Retrospective cohort mortality study of workers at an aircraft maintenance facility I. Epidemiological results. Br J Ind Med 1991; 48: 515-530.

69) Axelson O, Selden A, Andersson K, Hogstedt C. Updated and expanded Swedish cohort study on trichloroethylene and cancer risk. J Occup Med 1994; 36: 556-562.

70) Novotna E, David A, Málek B. An epidemiological study of the hepatic tumour incidence in persons working with trichloroethylene I. The negative result of retrospective investigations in persons with primary liver carcinoma [Czech]. Prac Lekarstvi 1979; $31: 121-123$.

71) Paddle GM. Incidence of liver cancer and trichloroethylene manufacture: Joint study by industry and a cancer registry. Brit Med J 1983; 286: 846.

72) Málek B, Krimanová B, Rodavá O. An epidemiological study of hepatic tumour incidence in subjects working with trichloroethylene: $\Pi$. Negative result of retrospective investigations of dry cleaners [Czech]. Pracov Lek 1979; 31: 124-126.

73) Fredriksson $M$, Bengtsson N-O, Hardell L, Axelson O. Colon cancer, physical activity, and occupational exposures, a case-control study. Cancer 1989; 63: 1838-1842. 